WSRC-RP-92-1092

NRTSC

NUCLEAR REACTOR TECHNOLOGY

AND SCIENTIFIC こOMPUTATIONS
KEYWORLS: CAVITATION

COOLING TOWER

RETENTION: PERMANENT

\title{
MINIMUM 186 BASIN LEVELS REQUIRED FOR OPERATION OF ECS AND CWS PUMPS
}

(U)

by

\author{
K. K. REEVES RKR \\ K. L. BARBOUR KLB
}

ISSUED: OCTOBER, 1992

KL Batrom

K. L. Barbour, Reviewing Officiai

\section{$10 / 9 / 92$}

Date

SRTC SAVANNAH RIVER TECHNOLOGY CENTER, AIKEN, SC 29808 Westinghouse Savannah River Company

Prepared for the U. S. Department of Energy under

Contract DE-AC08-89SR18035

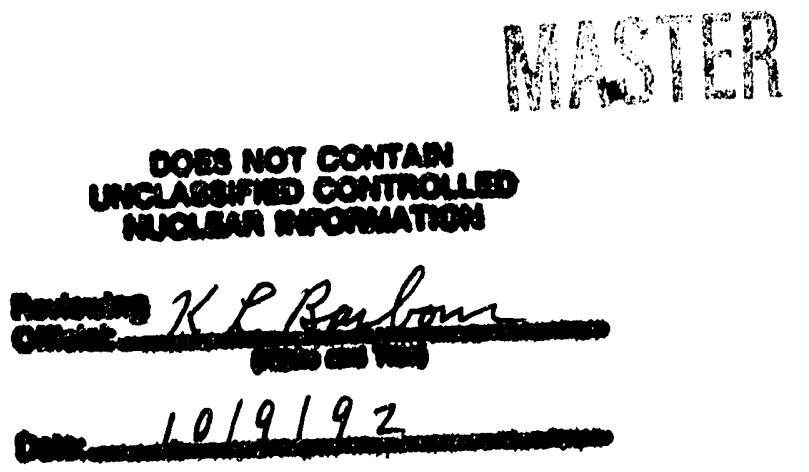


PROJECT: COOLING TOWER RELATED ANALYSES

DOCUMENT: WSRC-RP-92-1092

TITLE: MINIMUM 186 BASIN LEVELS REQUIRED FOR OPERATION OF ECS AND CWS PUMPS (U)

TASK: SMALL TASKS RELATED TO K REACTOR COOLING WATER BASIN OPERATION WITH A COOLING TOWER.

QA TASK NUMBER: $92-073-1$

REVISION NUMBER: 0

APPROVALS

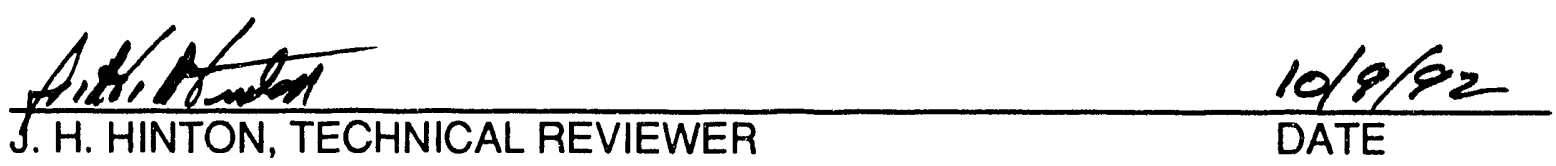

J.H. HINTON, TECHNICALREVIEWER

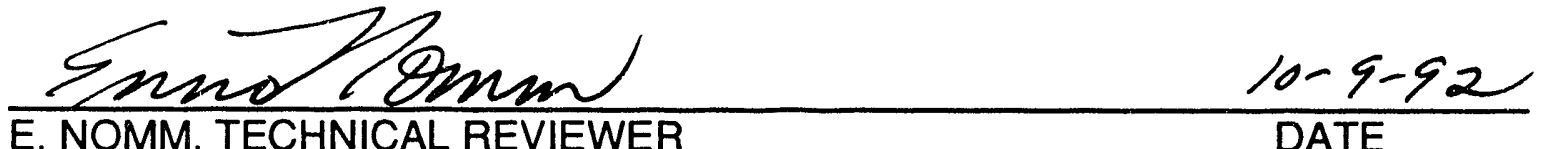

E. NOMM, TECHNICAL REVIEWER DATE

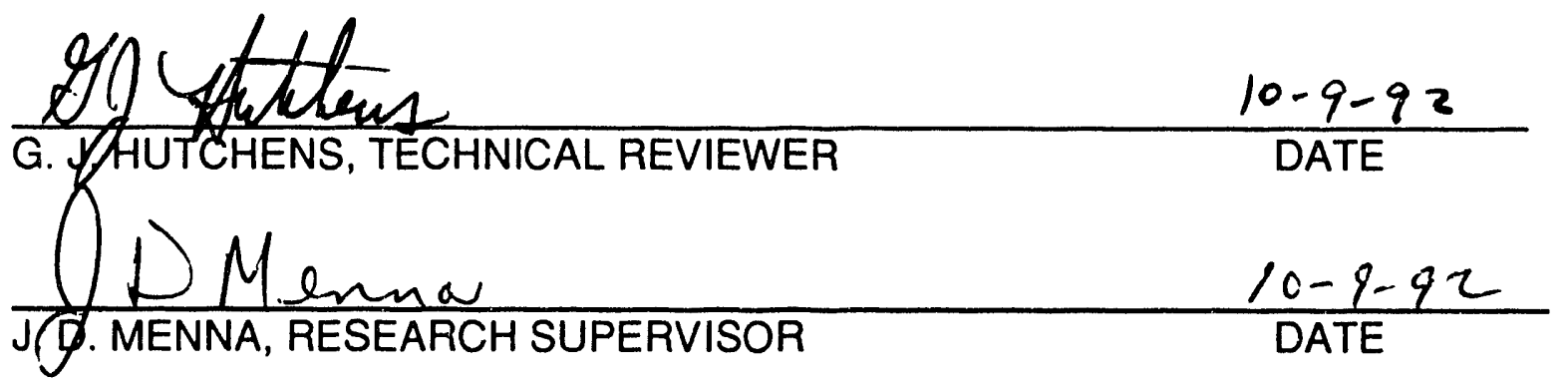

$$
\text { Qj Seavett } 10 / 13 / 92
$$

A. J. GARRETT, RESEARCH MANAGER 
WSRC-RP-92-1092

\section{TABLE OF CONTENTS}

\subsection{INTRODUCTION and SUMMARY}

2.0 DISCUSSION

2.1 Minimum Basin Level Calculation

2.2 Net Positive Suction Head Test Curves

2.3 Uncertainty

3.0 RESULTS

4.0 CONCLUSIONS

5.0 REFERENCES

TABLE

FIGURES

APPENDIX A - Sample Basin Level and Uncertainty Calculation

APPENDIX B - ECS and CWS PUmp Data
16

Page

1

2

2

4

5

8

9

10

12

13

22 
WSRC-RP-92-1092

\subsection{INTRODUCTION and SUMMARY}

Operation of $\mathrm{K}$ Reactor with a cooling tower requires that 186 Basin loss of inventory transients be considered during Design Basis Accident analyses requiring ECS injection, siıch as the LOCA and LOPA. Since the cooling tower systems are not considered safety systems, credit is not taken for their continued operation during a LOPA or LOCA even though they would likely continue to operate as designed. Without the continued circulation of cooling water to the 186 Basin by the cooling tower pumps, the 186 Basin will lose inventory until additional make-up can be obtained from the river water supply system. Increasing the make-up to the 186 Basin from the river water system may require the opening of manually operated valves, the starting of additional river water pumps, and adjustments of the flow to $L$ Area. In the time required for these actions a loss of basin inventory could occur.

The ECS and CWS pumps are supplied by the 186 Basin. A reduction in the basin level will result in decreased pump suction head. This reduction in suction head will result in decreased output from the pumps and, if severe enough could lead to pump cavitation for some configurations. The subject of this report is the minimum 186 Basin level required to prevent ECS and CWS pump cavitation. The reduction in ECS flow due to a reduced 186 Basin level without cavitation is part of a separate study [1].

Minimum basin levels required to prevent pump cavitation are presented in Table 1 for ECS A, ECS B, the Booster Pump, various ECS pump combinations, and the large and small 190 Building pumps. Results include $2 \sigma$ uncertainties and are calculated for a basin temperature of $90 \mathrm{~F}$ and with the pumps operating at maximum flow conditions. The mininum basin level for the 190 Building small and large pumps is the basin bottom. The limiting minimum basin level for combinations of ECS pumps is $-1.3 \pm 2.8$ (1.5 maximum) feet without the Process Room Spray System (PRSS) and $1.1 \pm 3.5$ (4.6 maximum) feet with the PRSS operating, where negative minimum basin levels imply the level can be reduced to basin bottom. The minimum basin level for the Booster Pump operating as a sole source is $1.1 \pm 3.0$ (4.1 maximum) feet without PRSS flow and $2.6 \pm 3.6$ (6.2 maximum) feet with PRSS flow. Considering uncertainties, ECS A and ECS B operated as sole sources at maximum flow rates require a full basin.

The minimum basin levels presented in Table 1 are based on cavitation due to inadequate NPSH. Vortex formation and the entrainment of air into the pump suction inlets could result in pump performance degradation at basin levels greater than those listed in Table 1 for some configurations. The suction line inlets for the ECS and small 190 Building pumps are similar to the suction inlet shown in Figure 1, with the opening located several feet below the basin bottom. With this arrangement air entrainment would not be expected until very low basin levels were reached. The large 190 Building pump suction inlets extend into the basin horizontally with a vertical bell shaped entrance with the top of the inlet at a basin level of about 2.75 feet. With this inlet configuration a basin level of at least 2.75 feet would be required to prevent the entrainment of 
air into the pump. A more detailed investigation of minimum basin leveis required to avoid significant air entrainment is being performed as part of a separate study.

\subsection{DISCUSSION}

\subsection{Minimum Basin Level Calculation}

The net positive suction head (NPSH) is defined as the total pump suction head referenced to the pump elevation minus the head due to fluid vapor pressure [2]. The minimum NPSH required to prevent detrimental vapor flashing in the pump, or cavitation, must be obtained from pump performance tests for each pump. To prevent cavitation in the field, the pump must be operated with an available NPSH greater than or equal to the required NPSH. For the pump and basin configuration shown in Figure 1, the available NPSH can be expressed as:

$$
\begin{aligned}
\text { NPSH } & =\text { Total Head } 2-\frac{P_{V}}{\gamma} \\
& =Z_{2}+\frac{P_{2}}{\gamma}+\frac{V_{2}^{2}}{2 g}-\frac{P_{v}}{\gamma}
\end{aligned}
$$

The mechanical energy equation between points 1 and 2 in Figure 1 can be written as:

$$
Z_{1}+\frac{P_{1}}{\rho g}+\frac{V_{1}^{2}}{2 g}=Z_{2}+\frac{P_{2}}{\gamma}+\frac{V_{2}^{2}}{2 g}+H_{f}
$$

Equation (2) and (3) can be combined to yield:

$$
\mathrm{NPSH}=Z_{1}+\frac{\mathrm{P}_{1}}{\gamma}+\frac{\mathrm{V}_{1}^{2}}{2 \mathrm{~g}}-\mathrm{H}_{\mathrm{f}}-\frac{\mathrm{P}_{\mathrm{V}}}{\gamma}
$$

Substitution of the pressure, velocity, and elevation (referenced to $\mathrm{Z}_{\mathrm{Cl}}$.) from Figure 1 into Equation (4) yields:

$$
\mathrm{NPSH}=\left(\mathrm{Z}_{\text {surf }}-\mathrm{Z}_{\mathrm{CL}}\right)+\frac{\mathrm{P}_{\mathrm{atm}}}{\gamma}+0-\mathrm{H}_{\mathrm{f}}-\frac{\mathrm{P}_{\mathrm{v}}}{\gamma}
$$

The elevation of the basin surface, $Z_{\text {surf, }}$ can be expressed as:

$$
Z_{\text {surf }}=B L+Z_{\text {Bot }}
$$


At the minimum allowable basin level the available NPSH will be equal to the required NPSH. Substituting Equation (6) into Equation (5) and rearranging yields:

$$
\mathrm{BL}=\mathrm{NPSH}+\mathrm{Z}_{\mathrm{CL}}-\mathrm{Z}_{\mathrm{Bot}}+\mathrm{H}_{\mathrm{f}}-\left(\frac{\mathrm{P}_{\mathrm{atm}}-\mathrm{P}_{\mathrm{v}}}{\gamma}\right)
$$

where: $\quad \mathrm{BL} \quad=$ minimum basin level,

$$
\begin{aligned}
& \text { NPSH }=\text { required pump NPSH, } \\
& \mathrm{ZCL}_{\mathrm{CL}}=\text { pump centerline elevation, }
\end{aligned}
$$$$
Z_{\text {Bot }}=186 \text { Basin bottom elevation, }
$$$$
\mathrm{H}_{f} \quad=\text { pump suction piping losses, }
$$

$P_{\text {atm }}=$ atmospheric pressure,

$P_{v} \quad=$ fluid vapor pressure (absolute), and,

$\gamma \quad=$ fluid specific weight $(\rho g)$.

Equation (7) is used to calculate the minimum 186 Basin level required to preclude pump cavitation. Details of the NPSH values used are given in Section 2.2. The ECS pump centerline elevations are scaled from drawings. The Booster Pump elevation is obtained from [3,4] and the centerline elevation of ECS A and B is scaled from [4,5]. The elevations used for the 190 Building pumps are given in [6]. The basin bottom elevation is given in [7]. These elevations are listed in Appendix A, Table A1.

The suction piping head losses are computed using PIPEFLOW Version 3.0 models. Details of the models used for both the ECS and 190 Building pumps are given in [8]. Comparisons of ECS pump suction piping losses computed using the PIPEFLOW model to K-Reactor test data [9] show good agreement for losses to ECS A and ECS B. Losses in the Booster Pump suction piping computed using PIPEFLOW are well below those calculated from the test data, even though flow to ECS A and ECS B follows the same path up to the Booster Pump room. Possible causes of this disagreement are being investigated.

The standard value of $14.7 \mathrm{psia}$ is used for the atmospheric pressure. The fluid vapor pressure and specific weight at $90 \mathrm{~F}$ were obtained from [10]. These values are also given in Table $\mathrm{A} 1$.

The total ECS flow rates used in the analysis $[4,11]$ are computed using the reactor vent path model and ECS FLOW code given in [12]. The flow rates are based on a LOPA scenario because the LOPA produces higher ECS flow rates later in the transient when a reduced 186 Basin level could occur. The ECS is throttled before a reduced basin level is of concern during a LOCA [13]. The ECS FLOW code supplies the total ECS flow rate. When the total flow rate is the sum of flows from multiple pumps the flow contribution of each operating pump is determined by locating the operating point on the ECS supply curve and then determining the individual flow rates from the supply curve data given in [14]. 
WSRC-RP-92-1092

\subsection{Net Positive Suction Head Test Curves}

The NPSH curve for the ECS A and B pumps is given in [15]. Reference 16 gives the NPSH curve for the ECS Booster Pump. These curves are shown in Figures 2 and 3.

A suction lift curve is given in [17] for the large 190 Building pumps. These data are assumed to represent the total required suction lift, which is defined as the elevation difference between the basin surface and pump plus the suction piping head losses at the onset of cavitation [2]. Referring to Figure 1, total suction lift (SL) can be written as:

$$
S L=Z_{C L}-Z_{\text {Surf }}+H_{f}
$$

Substitution of Equation (8) into Equation (5) yields:

$$
\mathrm{NPSH}=\left(\frac{\mathrm{P}_{\mathrm{atm}}-\mathrm{P}_{\mathrm{V}}}{\gamma}\right)-\mathrm{SL}
$$

The required NPSH for the large 190 Building pumps is calculated using Equation (9). The resulting required NPSH curve is shown in Figure 4.

A suction lift curve is given in [18] for a small 190 Building pump with a 22.625 inch diameter impeller. This suction lift curve increases as the flow rate increases and thus represents the total suction lift during the pump head tests instead of the suction lift at the onset of pump cavitation [19]. Currently, 25.25 inch diameter impellers are installed in the pumps [20]. The required NPSH for the large impeller would be expected to remain unchanged or decrease slightly.

Total suction lift data from [18] are used in Equation (9) to compute the NPSH available during the pump test. Since the pump head test was not performed with the pump cavitating, the available NPSH is greater than or equal to the required NPSH. The available NPSH is used in Equation (7) to obtain a conservative minimum 186 Basin level. The available NPSH curve is shown in Figure 5.

For comparison purposes, two Goulds pump NPSH curves [21] for pumps similar to the small 190 pumps are shown in Figure 5. The discharge head specifications and pump speeds are similar to the small 190 Building pumps; thus, the NPSH curves would also be similar. The NPSH curves of two Goulds pumps fall well below the available NPSH curve of the small 190 Building pumps used in the analysis.

Copies of the vendors test curves for the ECS and CWS pumps are given in Appendix $B$. The equations for the test data fits used in the minimum basin level calculations are given in Appendix A, Table A2. 


\subsection{Uncertainty}

The best estimate value of the minimum 186 Basin level required to prevent ECS or CWS pump cavitation is determined using Equation (7). A bounding fluid temperature of $90 \mathrm{~F}(32 \mathrm{C})$ is used in the analysis. At this temperature the fluid specific weight and vapor pressure are assumed to contain negligible uncertainty. The 186 Basin bottom elevation is also well known and is assumed to contain negligible uncertainty. The remaining parameters considered in the uncertainty analysis are the NPSH, $Z_{C L}, H_{f}$, and $P_{\text {atm. }}$.

At a fixed temperature the NPSH is a function of the flow rate, pump speed, and pump geometry. The suction piping losses are a function of the flow rate and piping geometry. Since NPSH and $\mathrm{H}_{f}$ are both functions of the flow rate, they are not independent variables. $\mathrm{ZCL}$ and $\mathrm{P}_{\mathrm{atm}}$ are independent of all other parameters. The correlation coefficient between the NPSH and suction piping losses is conservatively assumed to be 1.0 and the minimum basin level uncertainty is calculated from $[22,23]$ :

$$
\sigma_{\mathrm{BL}}^{2} \leq \sigma_{\mathrm{NPSH}}^{2}+\sigma_{\mathrm{Hf}}^{2}+\sigma_{\mathrm{ZCL}}^{2}+\frac{1}{\gamma^{2}} \sigma_{\mathrm{Patm}}^{2}+2 \sigma_{\mathrm{NPSH}} \sigma_{\mathrm{Hf}}
$$

For ECS configurations with multiple pumps operating, Equations (7) and (10) are applied to each pump.

The pump centerline elevations are scaled from drawings. The uncertainty in this scaling is assumed to be 0.5 feet for all pumps. The atmospheric pressure also varies somewhat depending on weather conditions and is assumed to have an uncertainty of $0.25 \mathrm{psi}(0.5 \mathrm{in} . \mathrm{Hg})$.

Test data is available from the pump vendors which give the NPSH as a function of the flow rate $(Q)$ only for a given pump, or:

$$
N P S H=f(Q)
$$

$\sigma_{\mathrm{NPSH}}^{2}$ is then calculated from [22,23]:

$$
\sigma_{\mathrm{NPSH}}^{2}=\left(\left.\frac{\partial N P S H}{\partial Q}\right|_{0} ^{2} \sigma_{\mathrm{Q}}^{2}\right.
$$

The partial derivative is determined from a fit of the vendors NPSH vs. flow rate data. The partial derivatives are also given in Appendix A, Table A2. The total ECS flow rate and total flow uncertainty $\left(\sigma_{Q}\right)$ are computed for a LOPA scenario using the ECS FLOW [12] code and ECS supply curves given in [14]. The flow uncertainty is a result of uncertainties in the ECS supply curve and in the loss coefficients and elevations of the reactor vent path components. 
The ECS FLOW [12] code computes the uncertainty associated with the total ECS flow rate; however, when the total flow rate is the sum of flows from multiple pumps, the flow rate uncertainties associated with the individual pumps are not determined. The flow contribution of each operating pump can be determined as explained in Section 2.1; however, the flow uncertainty attributable to each individual pump is not easily found. A conservative approach is used where the flow uncertainty of each pump is assumed to be equal to the total flow uncertainty. If the total flow rate was increased by $\sigma_{Q}$ with multiple pumps operating it would be expected that the flow rate produced by each pump would increase by approximately oo divided by the number of pumps operating since the pumps have similar characteristics. It is extremely unlikely that the flow rate produced by one pump would increase by more than $\sigma_{Q}$ while the flow rates of the remaining pumps decreased.

The suction piping head loss is computed using a PIPEFLOW 3.0 model [8]. At a fixed temperature the pump suction piping losses are a function of the flow rate and system geometn. The suction piping lengths and diameters are well defined and are assumed to result in negligible uncertainty when compared to the other parameters. The roughness of the pipe walls and the minor loss coefficients are considered in the uncertainty analysis. Thus:

$$
H_{f}=f\left(\varepsilon_{i}, K_{i}, Q\right)
$$

where: $\quad \varepsilon_{i,}=$ pipe wall roughness, and,

$K_{i}=$ pipe minor loss coefficients.

Since all pipes leading from the basin to the pumps are made of the same material and see the same service, the pipes would be expected to have the same surface characteristics. Therefore, the nominal roughness and roughness uncertainty are assumed to be identical for all pipes in the suction system. The minor losses associated with each pipe are considered independently.

$\sigma_{H_{f}}^{2}$ is calculated from:

$$
\sigma_{H+}^{2}=\left(\left.\frac{\partial H_{f}}{\partial \varepsilon}\right|_{0}\right)^{2} \sigma_{\varepsilon}^{2}+\sum_{i=1}^{n}\left(\left.\frac{\partial H_{f}}{\partial K_{i}}\right|_{0}\right)^{2} \sigma_{K_{i}}^{2}+\left(\left.\frac{\partial H_{f}}{\partial Q}\right|_{0}\right)^{2} \sigma_{Q}^{2}
$$

The right hand terms in Equation (14) are approximated by performing perturbation runs with the PIPEFLOW 3.0 model. The pipe roughness term can be found from:

$$
\left(\left.\frac{\partial H_{f}}{\partial \varepsilon}\right|_{0}\right)^{2} \sigma_{\varepsilon}^{2} \approx\left(\frac{H_{f: 0}-H_{f: \varepsilon}}{\varepsilon_{0}-\varepsilon}\right)^{2} \sigma_{\varepsilon}^{2}
$$


If the roughness value is perturbed by $\sigma_{\varepsilon}$, or;

$$
\varepsilon=\varepsilon_{0}+\sigma_{\varepsilon}
$$

Equation (15) can be reduced to:

$$
\left(\left.\frac{\partial H_{f}}{\partial \varepsilon}\right|_{0}\right)^{2} \sigma_{\varepsilon}^{2}=\left(H_{f, 0}-H_{f, \varepsilon}\right)^{2}
$$

Similarly:

$$
\begin{aligned}
\sum_{i=1}^{n}\left(\left.\frac{\partial H_{f}}{\partial K_{i}}\right|_{0}\right)^{2} \sigma_{K_{i}}^{2} \approx \sum_{i=1}^{n}\left(H_{f, 0}-H_{f, K_{i}}\right)^{2} \\
\text { where, } K_{i}=K_{i, 0}+\sigma_{K_{i}}
\end{aligned}
$$

and

$$
\begin{aligned}
\left(\left.\frac{\partial H_{f}}{\partial Q}\right|_{0}\right)^{2} \sigma_{Q}^{2} & \approx\left(H_{f, O}-H_{f, Q}\right)^{2} \\
\text { where, } Q & =Q_{0}+\sigma_{Q}
\end{aligned}
$$

Only one perturbation is made for the roughness term with the roughness of all pipes leading to the pump being studied perturbed by $\sigma_{\varepsilon}$. The pipe roughness is increased from a nominal value of 2.0 millifeet to 10.0 millifeet for the roughness perturbation. A separate perturbation run is made for the minor loss coefficient of each pipe leading to the pump being considered. The minor loss coefficients are increased by $50 \%$ for each pipe. Pipes with a nominal minor loss coefficient of zero have a minor loss coefficient of 0.25 added. A flow perturbation is also run for each operating pump. When more than one pump is being operated, the $H_{t, Q}$ term in Equation (19) is computed by increasing the flow rate to the pump being considered by $\sigma_{Q}$. This maximizes the increase in $H_{f}$ due to flow rate uncertainty for that pump.

The standard deviations are given as $\sigma$ 's in Equations (10) through (19), however, the values used in the analysis are considered $2 \sigma$ or greater. Sample uncertainty calculations are given in Appendix A. Additional details of the uncertainty analysis are given in $[22,23]$. 
WSRC-RP-92-1092

\subsection{RESULTS}

Table 1 presents the minimum 186 Basin levels required to avoid cavitation of the ECS pumps with each pump operating alone and for several pump combinations. Minimum basin levels are presented both with and without the PRSS operating. A negative minimum basin level means that the basin bottom is the minimum level. The minimum basin levels required for operation of the 190 Building pumps are also given in Table 1. Basin levels below the values presented in Table 1 are assumed to affect pump performance.

The results given in Table 1 show that all ECS configurations studied allow operation at reduced basin levels with the exception of ECS A alone or ECS B alone. The higher required basin levels and large uncertainties with ECS A or ECS B operating independently are due to the rapid increase in required NPSH at higher flow rates, as shown in Figure 2. Generally, single source ECS configurations are not relied on in safety analyses and power limit calculations.

In 1989 tests [9] were performed in K-Reactor in which the basin level was reduced while ECS A and ECS B were each operated alone at flow rates of about $12,700 \mathrm{gpm}$. The tests were terminated when pump noise increased significantly above background levels, which occurred at a basin level of 10.5 feet with ECS A operating and at a level of 10.25 feet with ECS B operating. At these basin levels there was no decrease in pump performance and it was suggested [9] that the basin level could be reduced another two to three feet before serious performance degradation would be expected. Calculations performed [4] using Equation (7) for ECS A and ECS B each operating alone at a flow rate of $12,700 \mathrm{gpm}$ with $60 \mathrm{~F}$ water resulted in best estimate minimum basin levels of 8.3 and 7.4 feet for ECS A and ECS B, respectively. These calculated basin levels agree favorably with the test results.

Results presented in Table 1 for the 190 Building pumps show that both small and large pumps can operate to the basin bottom in regard to inlet suction head requirements. However, inlet suction piping configuration for the large 190 pumps limits them to at least a minimum 2.75 foot level above basin bottom.

The minimum basin levels presented in Table 1 are based on pump performance degradation due to inadequate NPSH only and are computed for an elevated basin temperature and maximum flow rates. The flow rates used were computed for a basin level of 16.4 feet. The flow rate would decrease as the basin level decreases [1]. Thus, the actual minimum basin levels would be slightly less than those presented in Table 1 . The reduction in the pump suction well level as compared to the basin level due to flow through the travelling screens was not considered so the minimum basin levels given in Table 1 could be interpreted as minimum pump suction well levels.

Additional details of the minimum basin level and uncertainty calculations are given in [23]. 
WSRC-RP-92-1092

\subsection{CONCLUSIONS}

The minimum basin levels required to prevent decreased pump performance due to inadequate NPSH have been calculated for ECS A, ECS B, the Booster Pump, various ECS pump combinations, and the large and small 190 Building pumps. Results include $2 \sigma$ uncertainties and are calculated for a basin temperature of $90 \mathrm{~F}$ and with the pumps operating at maximum flow conditions. The results show that the 190 Building pumps can operate to the basin bottom with regard to inlet suction head requirements; however, the large 190 Building pumps have at least a 2.75 foot minimum basin level due to inlet piping configuration. The limiting minimum basin level for combinations of ECS pumps is $-1.3 \pm 2.8$ (1.5 maximum) feet without the PRSS and $1.1 \pm 3.5$ (4.6 maximum) feet with the PRSS operating. The minimum basin level for the Booster Pump operating as a sole source is $1.1 \pm 3.0$ (4.1 maximum) feet without PRSS flow and $2.6 \pm 3.6$ (6.2 maximum) feet with PRSS flow. Considering uncertainties, ECS A and ECS B operated as sole sources at maximum flow rates require a full basin. 
WSRC-RP-92-1092

\subsection{REFERENCES}

[1]. K. K. Reeves, "The Effect of Reduced 186 Basin Levels on ECS Supply Curves", NES-ART-920236, October 1992.

[2]. I. J. Karassik, et. al., Pumo Handbook, McGraw-Hill, Inc., 1976.

[3]. Drawing W234897.

[4]. K. K. Reeves, "Calculations For Pump Cavitation Analysis", Research Notebook WSRC-NB-92-78, August 1992.

[5]. Drawing W133726.

[6]. N. T. Hightower III, "Cooling Water and Emergency Cooling System Model for Savannah River Simulator (SARIS) Benchmark Calculations", DPST-82-1002, January 20, 1984.

[7]. Drawing W139214.

[8]. K. K. Reeves, "PIPEFLOW 3.0 Models of ECS and CWS Pump Suction Piping", NES-ART-920306, October 1992.

[9]. G. B. O'Briant, "1989 Hydraulic Tests of ECS With a Fourth Addition System - K Reactor", RTR-2685, February 1990.

[10]. Crane Co., Technical Paper No. 410, Appendix A.

[11]. Reeves, K. K., "ECS Flow Rates for ECS Pump Cavitation Calculations," Savannah River Company Memorandum, NES-ART-920227, July 16, 1992.

[12]. K. K. Reeves and D. T. Herman, "Maximum ECS Flow Rates and Reactor Tank Pressures During a LOPA", WSRC-RP-91-947, February 1992.

[13]. N. H. Kuehn, "Analysis of Long Term Cooling Following a LOCA", WSRCTR-91-463, July 1991.

[14]. J. D. Sterrett, J. W. Reece, and D. A. Burge, "Emergency Cooling System Supply Curves and PIPEFLOW Version 1 Benchmark Calculations", WSRC-TR-91-6009, January 1992.

[15]. J. H. Hinton, "Net Positive Suction Head for ECS Pumps," DuPont Company, Savannah River Plant Memorandum, November 2, 1987.

[16]. BPF 211378.

[17]. BPF 210825. 
[18]. BPF 202271.

[19]. T. C. Andes, "NPSH Required for Building 190 Worthington Pumps", RRD-RED-920655, August 26, 1992.

[20]. T. C. Andes, "Cooling Water Pump Performance Testing, BLDG. 190K", WSRC-TR-91-42-021, April 15, 1991.

[21]. Goulds Pumps, Inc., Goulds Pump Manual, 3rd Edition.

[22]. B. J. Hardy, "Minimum Basin Level Uncertainty Methodology Development", Research Notebook WSRC-NB-91-220, Pages 102-105, August 1992.

[23]. K. K. Reeves and K. L. Barbour, "Calculations to Determine Minimum 186 Basin Levels Required For Operation of ECS and CWS Pumps", CalcNote ARTCN-92002, October 1992. 


\section{TABLE 1}

\section{Summary of Minimum Basin Level Calculation Results}

\begin{tabular}{|c|c|c|c|c|c|}
\hline $\begin{array}{c}\text { Sources On } \\
\text { (Total Flow, gpm) }\end{array}$ & Pump & $\begin{array}{l}\text { Pump Flow } \\
\text { Rate, gpm }\end{array}$ & $\begin{array}{c}\text { Minimum } \\
\text { Best } \\
\text { Estimate }\end{array}$ & $\begin{array}{l}\text { Basin } \\
2 \sigma\end{array}$ & $\begin{array}{l}\text { Level }^{\star}, \text { fee } \\
\text { Worst } \\
\text { Case }\end{array}$ \\
\hline $\bar{B} \bar{P}-$ & $=$ & $\overline{13,470}$ & 1.1 & 3.0 & 4.1 \\
\hline $\begin{array}{l}\text { BP, PRSS } \\
(15,770)\end{array}$ & $\begin{array}{l}\text { BP } \\
\text { PRSS }\end{array}$ & $\begin{array}{r}13,470 \\
2,300\end{array}$ & 2.6 & 3.6 & 6.2 \\
\hline $\mathbf{A}$ & - & 12,820 & 10.6 & 9.3 & 19.9 \\
\hline $\begin{array}{l}\text { A, PRSS } \\
(15,120)\end{array}$ & $\begin{array}{l}\text { A } \\
\text { PRSS }\end{array}$ & $\begin{array}{r}12,820 \\
2,300\end{array}$ & 16.0 & 10.0 & 26.0 \\
\hline B & - & 12,380 & 4.9 & 7.5 & 12.4 \\
\hline $\begin{array}{l}\text { B, PRSS } \\
(14,680)\end{array}$ & $\begin{array}{l}\text { B } \\
\text { PRSS }\end{array}$ & $\begin{array}{r}12,380 \\
2,300\end{array}$ & $\begin{array}{l}7.3 \\
-\end{array}$ & 8.0 & 15.3 \\
\hline$\underset{(16,200)}{\mathbf{A}, \mathbf{B}}$ & $\begin{array}{l}\mathrm{A} \\
\mathrm{B}\end{array}$ & $\begin{array}{l}8,100 \\
8,100\end{array}$ & $\begin{array}{l}-6.8 \\
-6.4\end{array}$ & $\begin{array}{l}4.1 \\
4.0\end{array}$ & $\begin{array}{l}-2.7 \\
-2.4\end{array}$ \\
\hline $\begin{array}{l}\text { A, B, PRSS } \\
(18,500)\end{array}$ & $\begin{array}{l}\text { A } \\
\text { B } \\
\text { PRSS }\end{array}$ & $\begin{array}{l}8,100 \\
8,100 \\
2,300\end{array}$ & $\begin{array}{l}-1.5 \\
-2.0 \\
-\end{array}$ & $\begin{array}{l}5.2 \\
5.0\end{array}$ & $\begin{array}{l}3.7 \\
3.0\end{array}$ \\
\hline$\underset{(16,230)}{\mathbf{A}, \mathbf{B P}}$ & $\begin{array}{l}\mathrm{A} \\
\mathrm{BP}\end{array}$ & $\begin{array}{l}8,200 \\
8,030\end{array}$ & $\begin{array}{r}-10.8 \\
-2.3\end{array}$ & $\begin{array}{l}3.8 \\
2.5\end{array}$ & $\begin{array}{r}-7.0 \\
0.2\end{array}$ \\
\hline $\begin{array}{l}\text { A, BP, PRSS } \\
(18,530)\end{array}$ & $\begin{array}{l}\text { A } \\
\text { BP } \\
\text { PRSS }\end{array}$ & $\begin{array}{l}8,200 \\
8,030 \\
2,300\end{array}$ & $\begin{array}{r}-6.2 \\
0.6 \\
-\end{array}$ & $\begin{array}{l}4.6 \\
3.1\end{array}$ & $\begin{array}{r}-1.6 \\
3.7\end{array}$ \\
\hline $\begin{array}{l}\mathbf{A}, \mathbf{B}, \mathbf{B P} \\
(17,380)\end{array}$ & $\begin{array}{l}\mathrm{A} \\
\mathrm{C} \\
\mathrm{BP}\end{array}$ & $\begin{array}{l}5,960 \\
6,190 \\
5,230\end{array}$ & $\begin{array}{r}-10.8 \\
-10.5 \\
-1.3\end{array}$ & $\begin{array}{l}3.8 \\
3.6 \\
2.8\end{array}$ & $\begin{array}{r}-7.0 \\
-6.9 \\
1.5\end{array}$ \\
\hline $\begin{array}{l}\text { A, B, BP, PRSS } \\
(19,680)\end{array}$ & $\begin{array}{l}\text { A } \\
\text { B } \\
\text { BP } \\
\text { PRSS }\end{array}$ & $\begin{array}{l}5,960 \\
6,190 \\
5,230 \\
2,300\end{array}$ & $\begin{array}{r}-6.1 \\
-6.6 \\
1.1 \\
-\end{array}$ & $\begin{array}{l}4.6 \\
4.4 \\
3.5\end{array}$ & $\begin{array}{r}-1.5 \\
-2.1 \\
4.6\end{array}$ \\
\hline Small 190 Pump & - & 14,160 & -4.7 & 1.1 & -3.6 \\
\hline Large 190 Pump & - & 30,000 & -2.4 & 1.5 & -0.9 \\
\hline
\end{tabular}




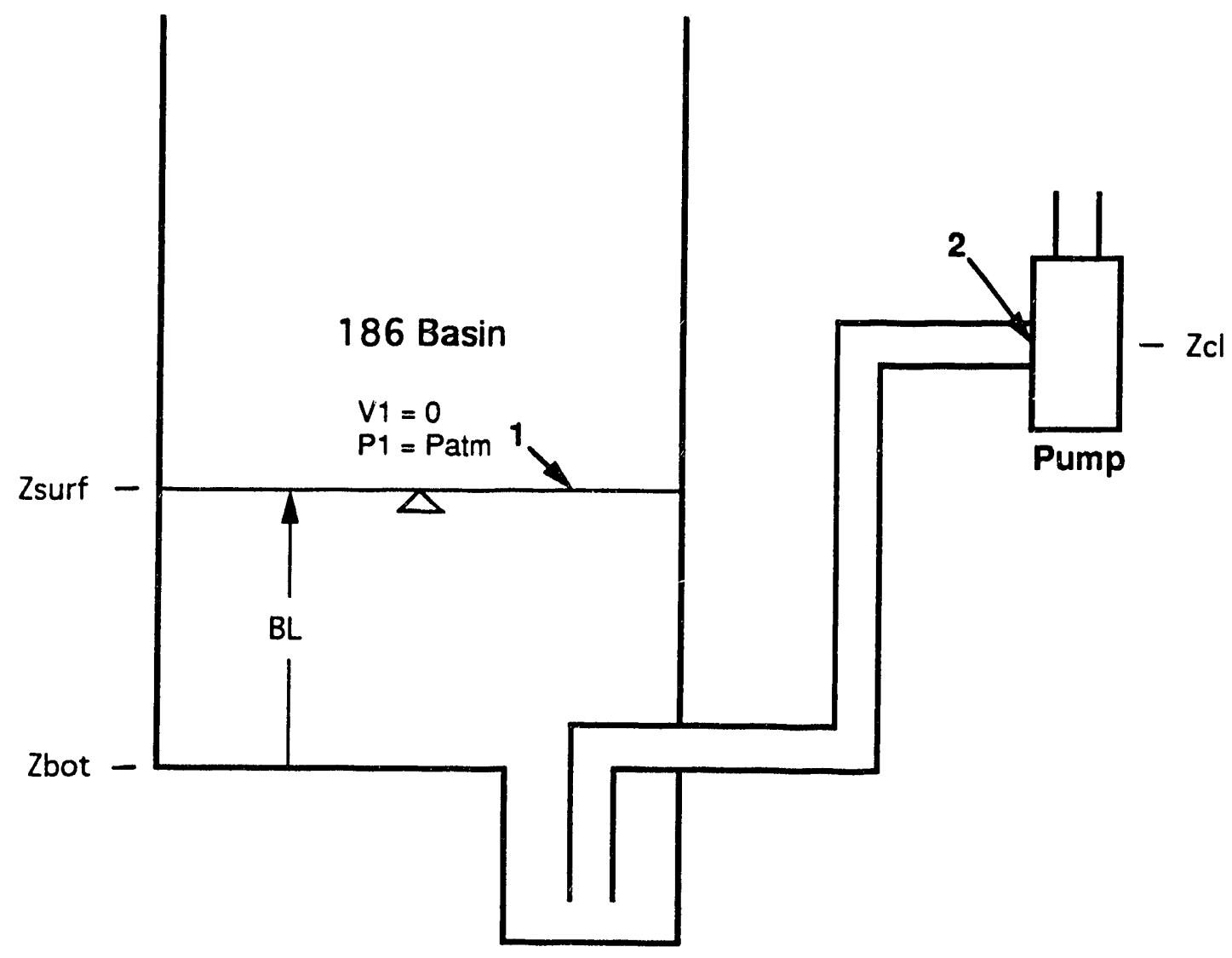

$\begin{array}{ccc}\text { Node } & \begin{array}{c}\text { Elevation } \\ \text { Referenced to } \\ \text { Sea Level }\end{array} & \begin{array}{c}\text { Elevation } \\ \text { Referenced to } \\ \text { Pump Centerline }\end{array} \\ 2 & \frac{Z_{\text {surf }}}{Z_{\text {surf }}-Z_{C L}} & 0\end{array}$

Figure 1. Schematic of pump and basin arrangement. 
WSRC-RP-92-1092

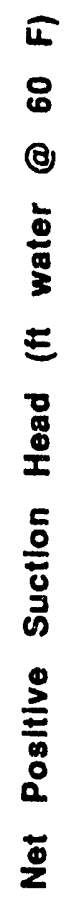

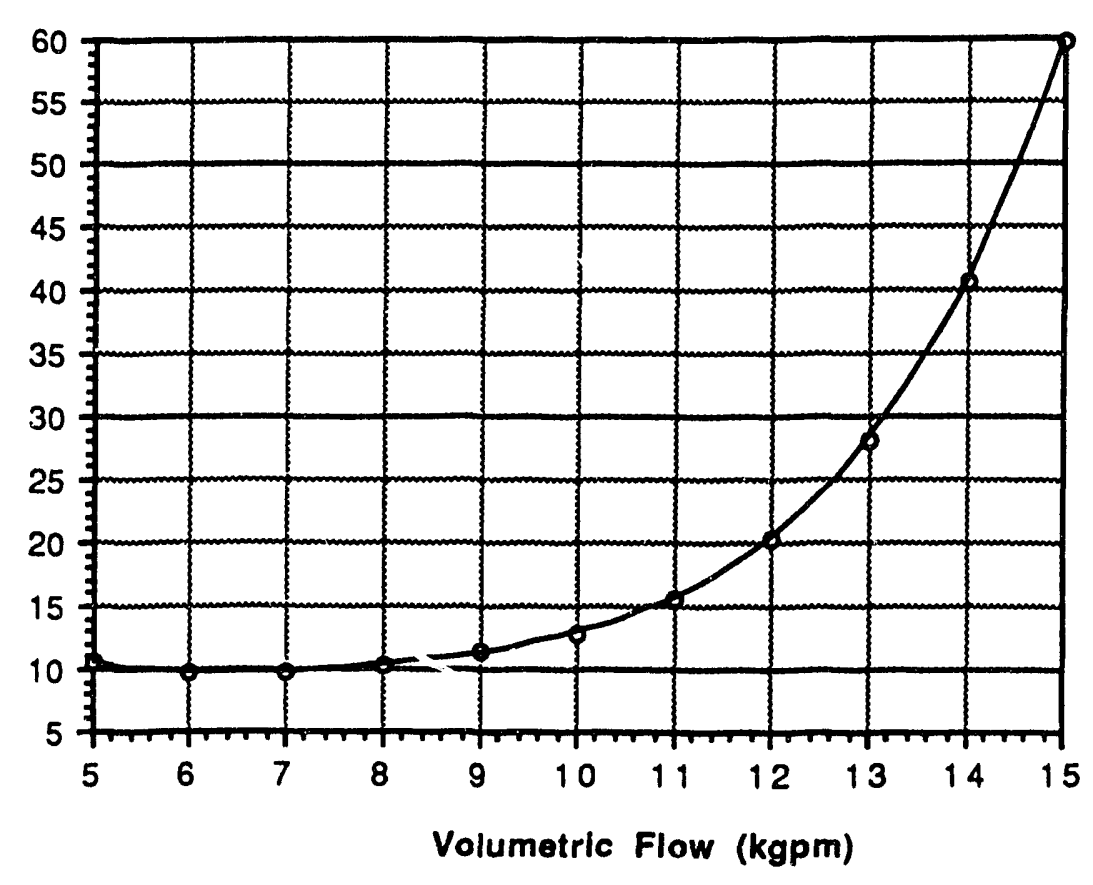

Figure 2. NPSH for ECS Pumps A \& B

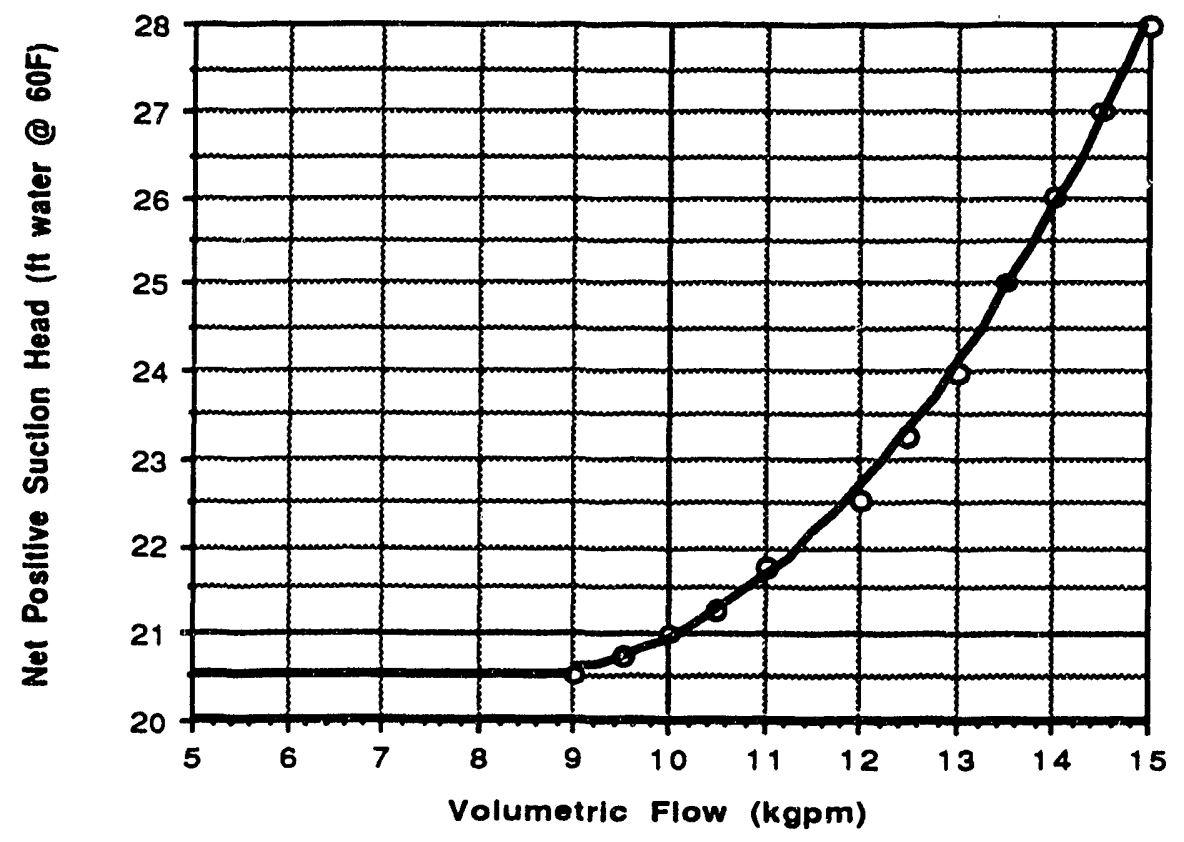

Figure 3. Booster Pump MPSH 


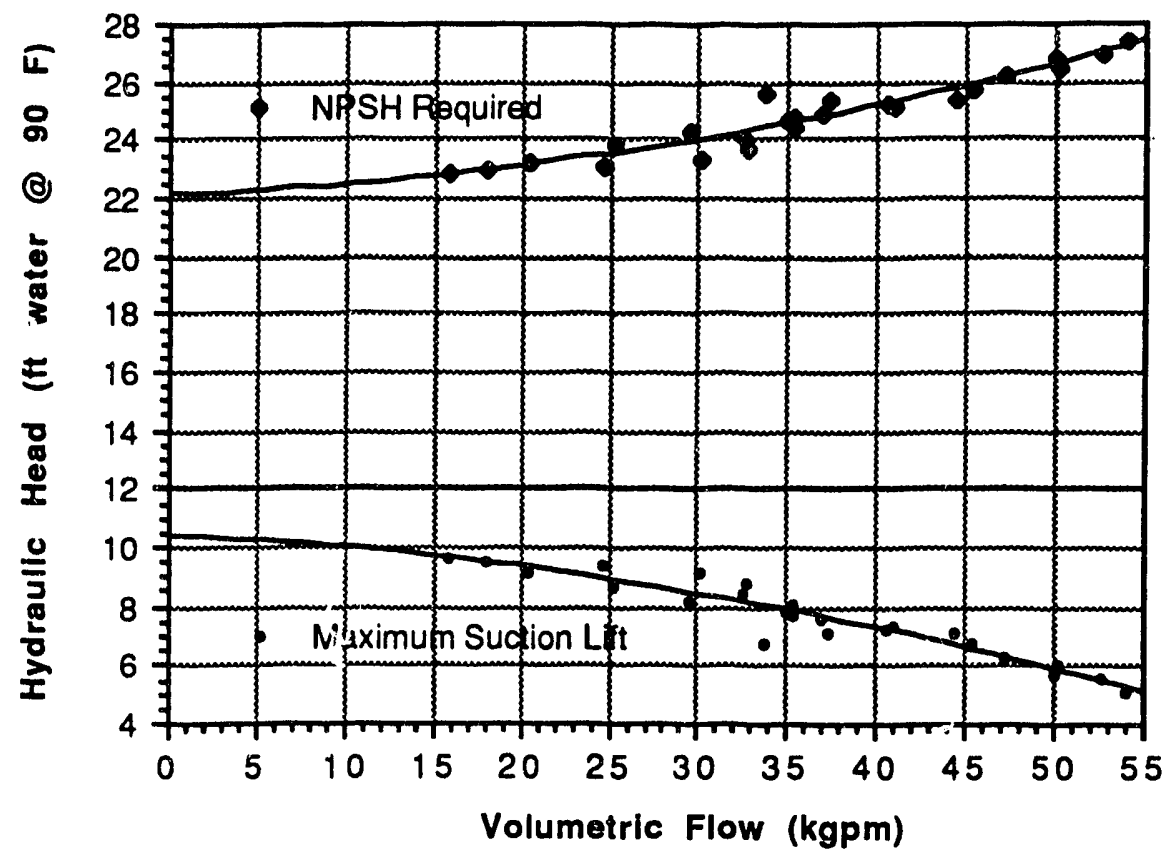

Figure 4. NPSH for Large 190 Pumps

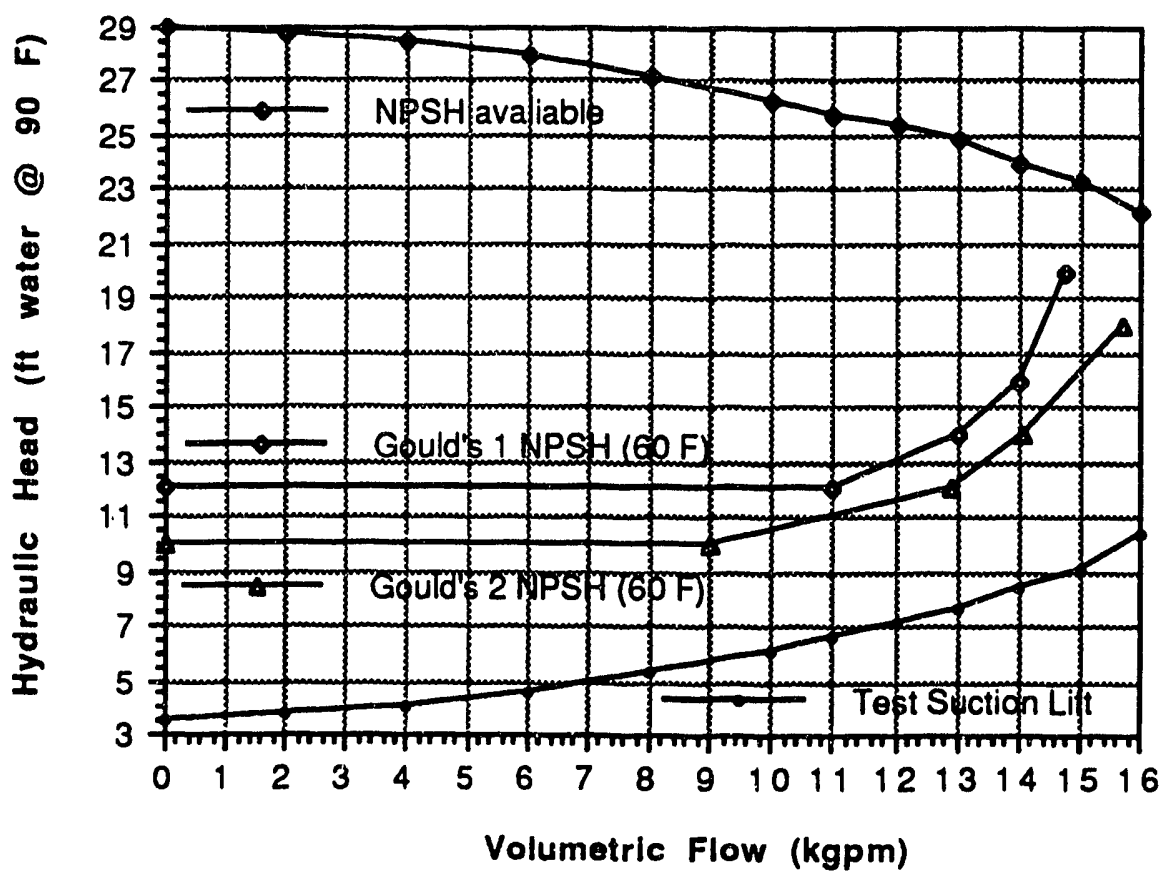

Figure 5. NPSH for Small 190 Pumps 
WSRC-RP-92-1092

\section{Appendix A}

Sample Minimum Basin Level and Uncertainty Calculations 
WSRC-RP-92-i 092

\section{Sample Calculation For Booster Pump Operating Alone}

Summary of Results

\begin{tabular}{cccc} 
& \multicolumn{3}{c}{ Best } \\
Parameter & Unit & Estimate & $\sigma(\geq 2 \sigma)$ \\
\hline $\mathrm{Q}$ & $\mathrm{kgpm}$ & 13.47 & 0.66 \\
$\mathrm{NPSH}$ & $\mathrm{tt}$ & 24.87 & 1.18 \\
$\mathrm{ZCL}$ & $\mathrm{ft}$ & 260.4 & 0.5 \\
$\mathrm{Z}_{\mathrm{Bot}}$ & $\mathrm{ft}$ & 258.5 & 0 \\
$\mathrm{H}_{f}$ & $\mathrm{ft}$ & 6.76 & 1.74 \\
$\mathrm{P}_{\mathrm{atm}}$ & $\mathrm{lb} / \mathrm{ft}^{2}$ & $14.7(144)$ & $0.25(144)$ \\
$\mathrm{Pv}_{\mathrm{V}}$ & $\mathrm{lb} / \mathrm{ft}^{2}$ & $0.70(144)$ & 0 \\
$\gamma$ & $\mathrm{lb} / \mathrm{ft}^{3}$ & 62.1 & 0 \\
$\mathrm{BL}$ & $\mathrm{tt}$ & 1.07 & 3.02
\end{tabular}

NPSH

From curve fit of vendors data:

$$
\begin{aligned}
& \mathrm{NPSH}=26.083-1.0507(13.47)+0.0029840(13.47)^{2}+0.0050712(13.47)^{3} \\
& =24.87 \mathrm{ft} \\
& \sigma_{\mathrm{NPSH}}^{2} \quad=\left(\left.\frac{\partial N P S H}{\partial Q}\right|_{0}\right)^{2} \sigma_{Q}^{2} \\
& =\left[-1.0507+0.0059680(13.47)+0.0152136(13.47)^{2}\right]^{2}(0.66)^{2} \\
& \sigma_{\mathrm{NPSH}} \quad=1.18 \mathrm{ft}
\end{aligned}
$$

$\underline{H}_{f}$

A schematic of the PIPEFLOW 3.0 ECS piping suction model is shown in Figure A1.

From the baseline or best estimate PIPEFLOW run:

$\mathrm{H}_{\mathrm{f}}=$ Basin Energy Grade (surface elevation) - Node 3 Energy Grade $=274.92-268.16=6.76 \mathrm{ft}$

PIPEFLOW Roughness and Minor Loss Coefficient Perturbations:

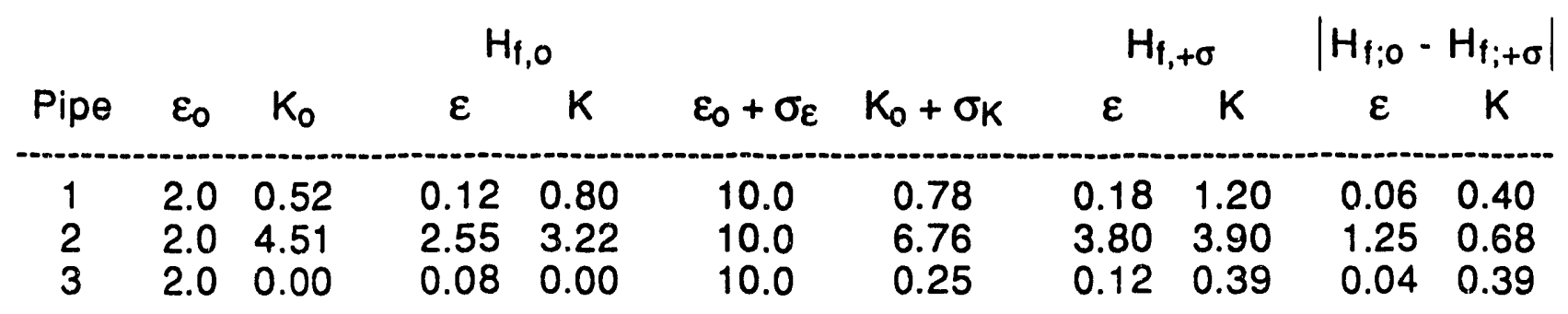


where:

$$
\begin{aligned}
& \varepsilon_{0}=\text { best estimate roughness, } \\
& \mathrm{K}_{0} \quad=\text { best estimate minor loss coefficient, } \\
& \mathrm{H}_{\mathrm{f}, \mathrm{O}} \quad=\text { best estimate pipe head loss due to wall friction }(\varepsilon) \text { and } \\
& \text { minor losses }(K) \text {, } \\
& \varepsilon_{0}+\sigma_{\varepsilon} \quad=\text { roughness perturbed by } \sigma \text {, } \\
& \mathrm{K}_{\mathrm{O}}+\sigma_{\mathrm{K}} \quad=\text { minor loss coefficient roughness perturbed by } \sigma \text {, } \\
& H_{f_{1}+\sigma}=\text { perturbed pipe head loss due to wall friction }(\varepsilon) \text { and minor }
\end{aligned}
$$

\section{PIPEFLOW Flow Rate Perturbation:}

PIPEFLOW model run with perturbed Booster Pump flow rate:

$$
Q=Q_{0}+\sigma_{Q}=13.47+0.66=14.13 \mathrm{kgpm}
$$

Resulting head loss to Booster Pump:

$$
\begin{gathered}
H_{f}=274.92-267.50=7.42 \mathrm{ft} \\
\left|H_{f ; 0}-H_{f ;+\sigma}\right|=|6.76-7.42|=0.66 \mathrm{ft} \\
\sigma_{H_{f}}^{2}=\left(\left.\frac{\partial H_{f}}{\partial \varepsilon}\right|_{0}\right)^{2} \sigma_{\varepsilon}^{2}+\sum_{i=1}^{n}\left(\left.\frac{\partial H_{f}}{\partial K_{i}}\right|_{0}\right)^{2} \sigma_{K_{i}}^{2}+\left(\left.\frac{\partial H_{f}}{\partial Q}\right|_{0}\right)^{2} \sigma_{Q}^{2} \\
\approx\left(H_{f, 0}-H_{f, \varepsilon}\right)^{2}+\sum_{i=1}^{n}\left(H_{f, 0}-H_{f, K_{i}}\right)^{2}+\left(H_{f, 0}-H_{f, Q}\right)^{2} \\
\approx(0.06+1.25+0.04)^{2}+(0.40)^{2}+(0.68)^{2}+(0.39)^{2}+(0.66)^{2} \\
\sigma_{H_{f}}=1.74 \mathrm{ft} .
\end{gathered}
$$

$\mathrm{BL}$

$$
\begin{aligned}
B L & =N P S H+Z_{C L}-Z_{B o t}+H_{f}-\left(\frac{P_{\text {atm }}-P_{v}}{\gamma}\right) \\
& =24.87+260.4-258.5+6.76-(14.7-0.7) \frac{144}{62.1} \\
& =1.07 \mathrm{ft}
\end{aligned}
$$


$\sigma_{\mathrm{BL}}^{2} \leq \sigma_{\mathrm{NPSH}}^{2}+\sigma_{\mathrm{Hf}}^{2}+\sigma_{\mathrm{ZCL}}^{2}+\frac{1}{\gamma^{2}} \sigma_{\mathrm{Patm}}^{2}+2 \sigma_{\mathrm{NPSH}} \sigma_{\mathrm{Hf}}$

$\leq(1.18)^{2}+(1.74)^{2}+(0.50)^{2}+\left(\frac{0.25(144)}{62.1}\right)^{2}+2(1.18)(1.74)$

$\sigma_{\mathrm{BL}} \quad \leq 3.02 \mathrm{ft}$ 


\section{Table A1}

\section{Parameter Values}

\begin{tabular}{lcccc}
\multicolumn{1}{c}{ Parameter } & Unit & Value & Reference & $2 \sigma$ \\
$Z_{C L}:$ ECS A & feet & 257.0 & {$[4,5]$} & 0.5 \\
$Z_{C L}$ : ECS B & feet & 257.0 & {$[4,5]$} & 0.5 \\
$Z_{C L}$ : Booster Pump & feet & 260.4 & {$[3,4]$} & 0.5 \\
$Z_{C L}$ : Small 190 & feet & 260.6 & {$[6]$} & 0.5 \\
$Z_{C L}$ : Large 190 & feet & 260.5 & {$[6]$} & 0.5 \\
$Z_{\text {Bot }}$ & feet & 258.5 & {$[7]$} & 0 \\
$P_{\text {atm }}$ & psia & 14.7 & std & 0.25 \\
$P_{V}$ & psia & .70 & {$[10]$} & 0 \\
$\gamma$ & lb $/ f_{\mathrm{ft}}{ }^{3}$ & 62.1 & {$[10]$} & 0
\end{tabular}

\section{Table A2}

\section{NPSH Curve Fits}

ECS $A$ and ECS $B$

NPSH $=67.905-28.569 Q+5.2157 Q^{2}-0.42641 Q^{3}+0.013549 Q^{4}$ $\frac{\partial N P S H}{\partial Q}=-28.569+10.431 Q-1.2792 Q^{2}+0.054196 Q^{3}$

\section{Booster Pump}

NPSH $=26.083-1.0507 Q+0.0029840 Q^{2}+0.0050712 Q^{3}$, for $Q>9.0$ $\mathrm{NPSH}=20.5$, for $\mathrm{Q} \leq 9.0$

$\frac{\partial N P S H}{\partial Q}=-1.0507+0.0059680 Q+0.0152136 Q^{2}$, for $Q>9.0$

$\frac{\partial N P S H}{\partial Q}=0$, for $Q \leq 9.0$

\section{Small 190 Building Pump}

NPSH (available) $=28.95-0.02652 \mathrm{Q}^{2}$

$\frac{\partial N P S H}{\partial Q}$ - not applicable since NPSHA is used as bounding value

Large 190 Building Pump

$\mathrm{NPSH}=22.069+0.024962 \mathrm{Q}+0.0013108 Q^{2}-1.7794\left(10^{-7}\right) Q^{3}$

$\frac{\partial N P S H}{\partial Q}=0.024962+0.0026216 Q-5.3382\left(10^{-7}\right) Q^{2}$

All equations for NPSH in feet and $Q$ in kgpm. 


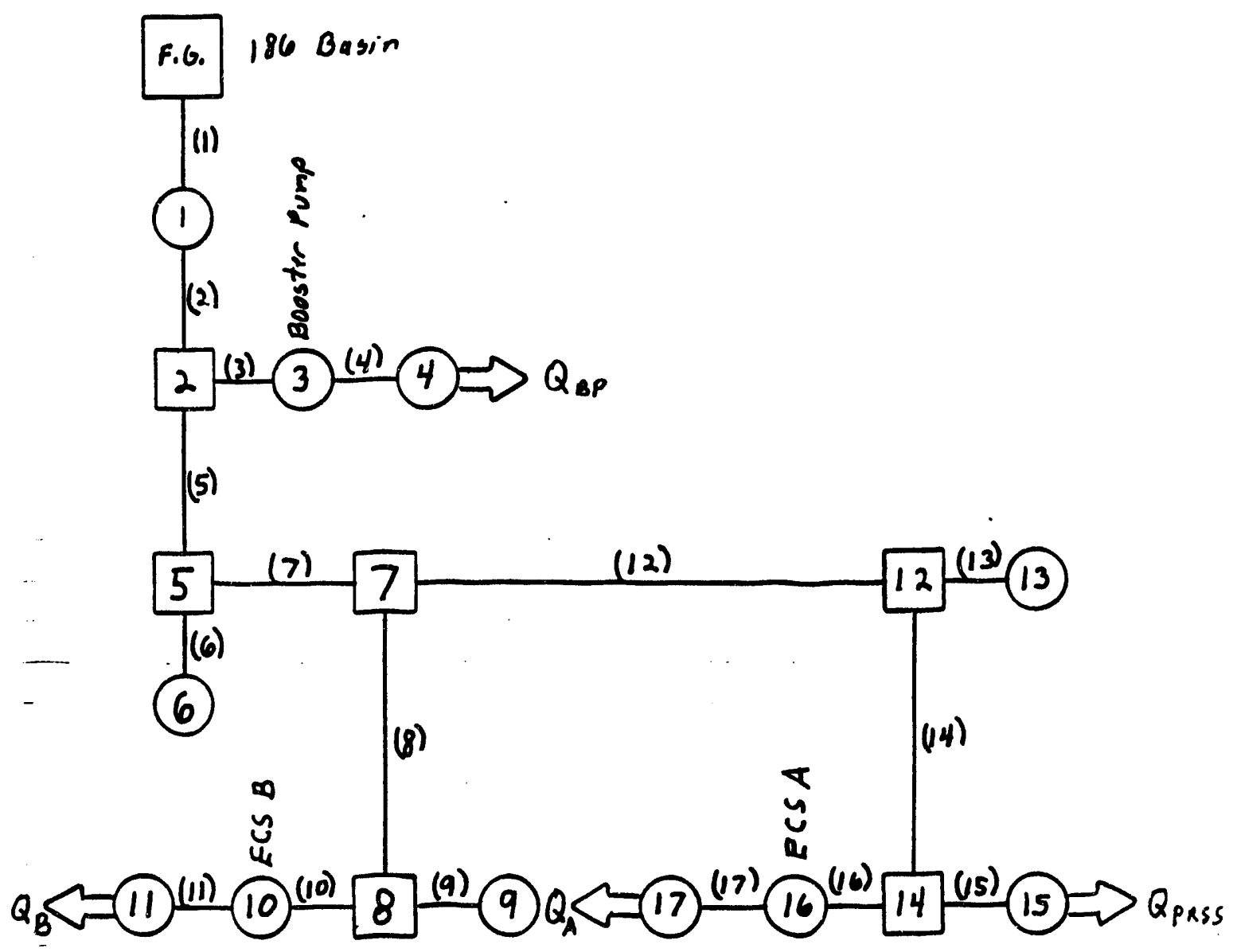

Figure A1. Schematic of PIPEFLOW 3.0 ECS pump suction piping model [8]. 
WSRC-RP-92-1092

\section{Appendix B}

\section{ECS and CWS Pump Data}


WSRC-RP-92-1092
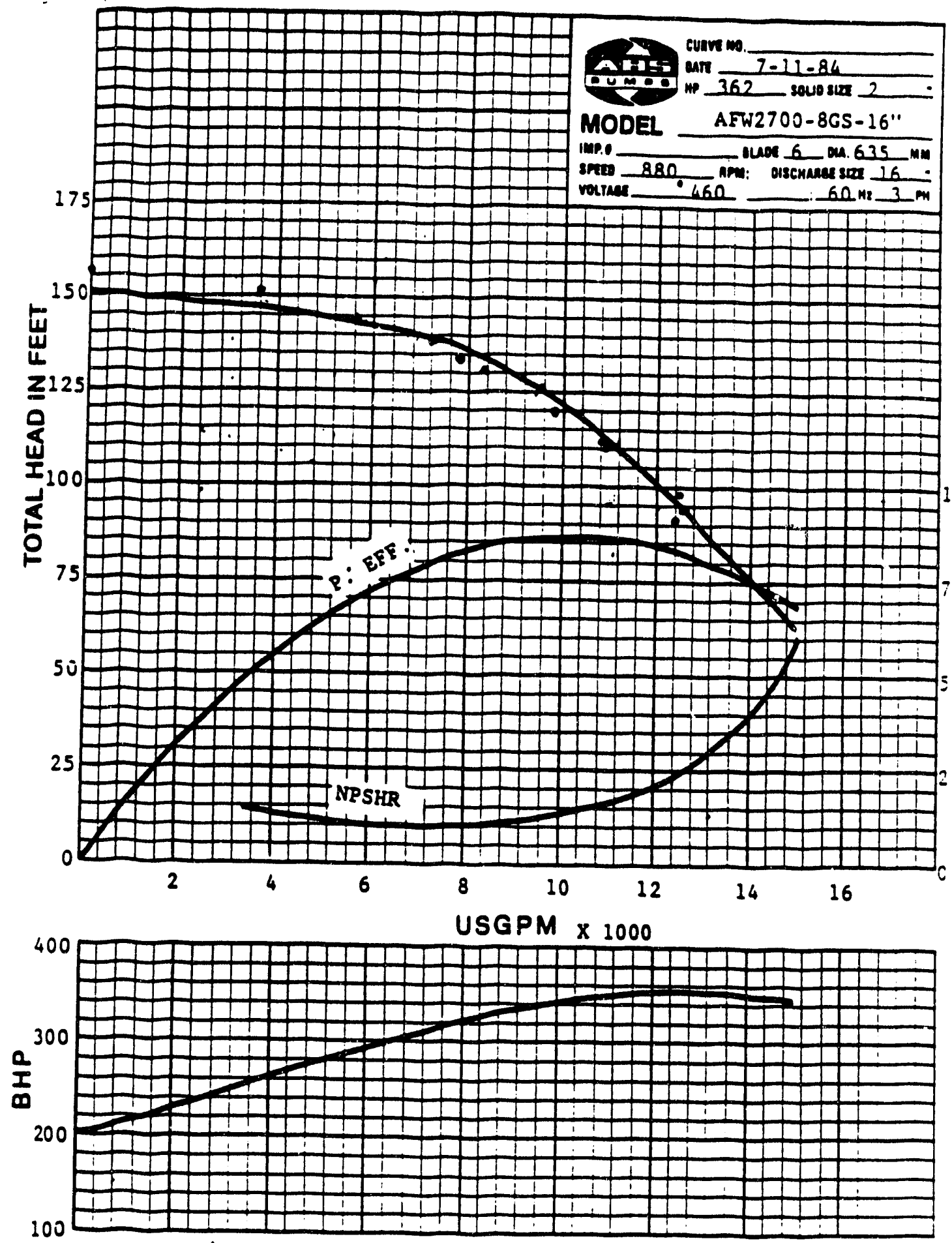

Nespunger the

Figure B1. ECS A and ECS B vendor pump test curves [15]. 


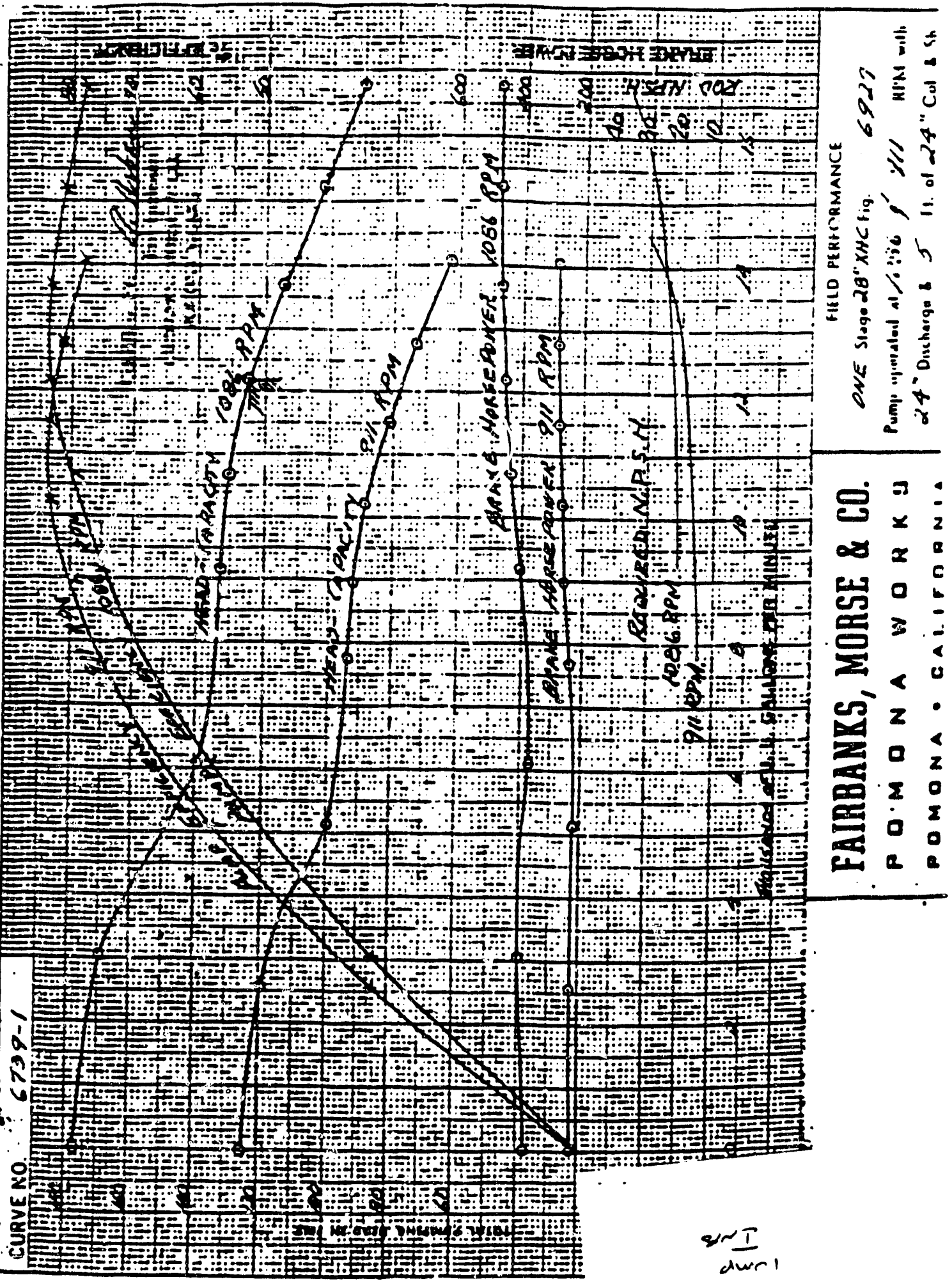

Figure B2. Buoster Pump vendor test curves [16]. 


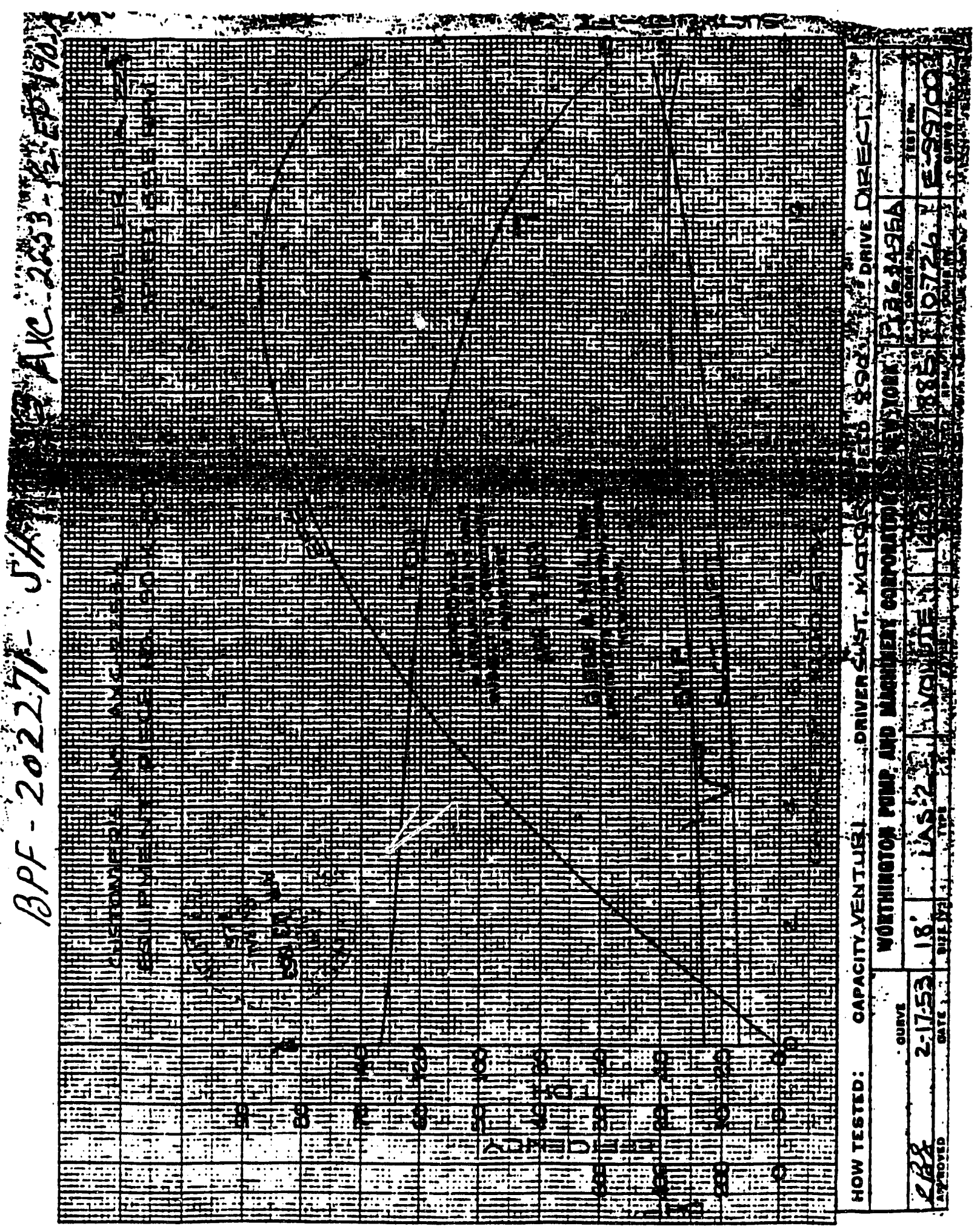

Figure B3. Small 190 Building pump vendor test curves [18]. 
WSRC-RP-92-1092

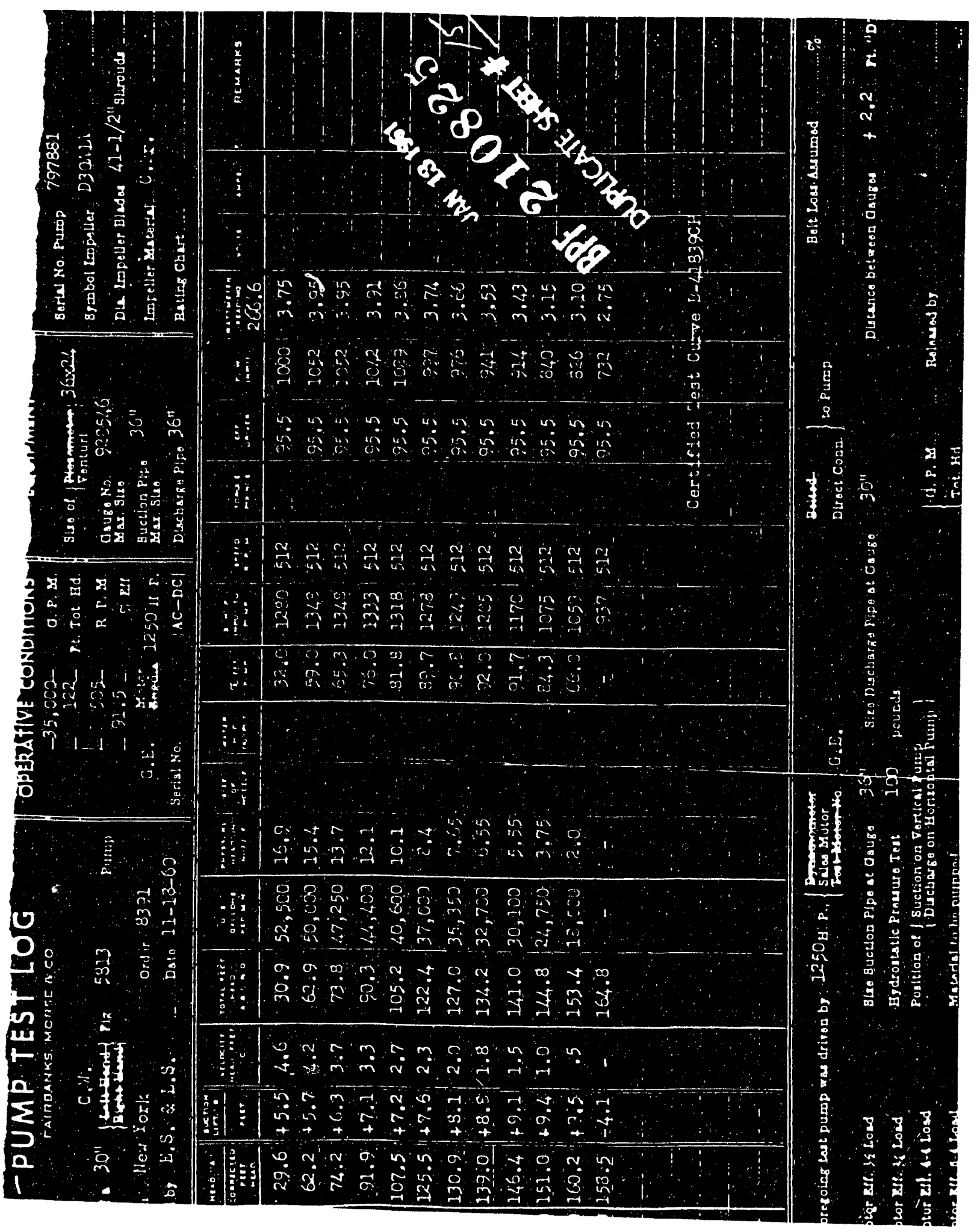

Figure B4. Large 190 Building pump vendor test data [17]. 

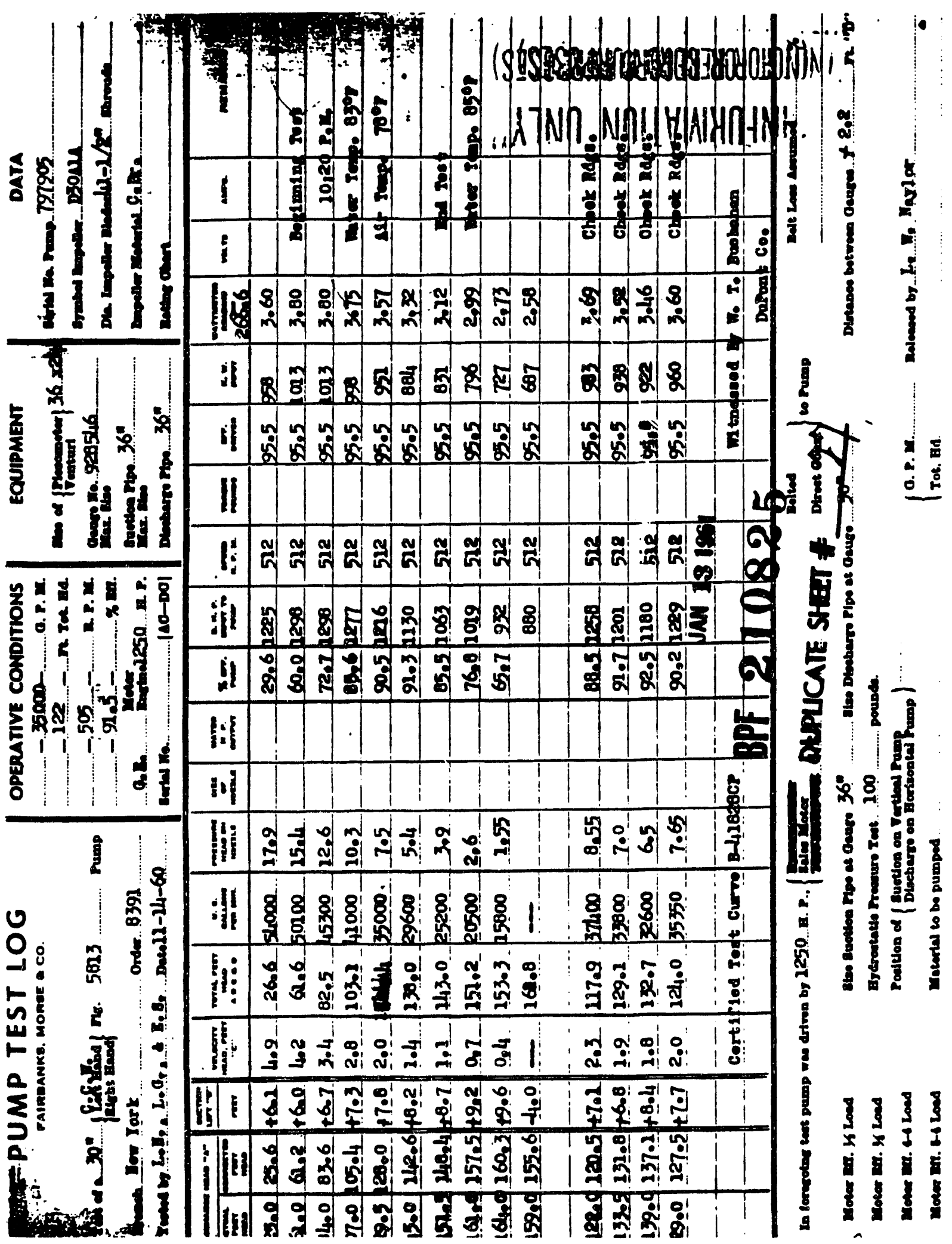

Figure B5. Large 190 Building pump vendor test data [17]. 

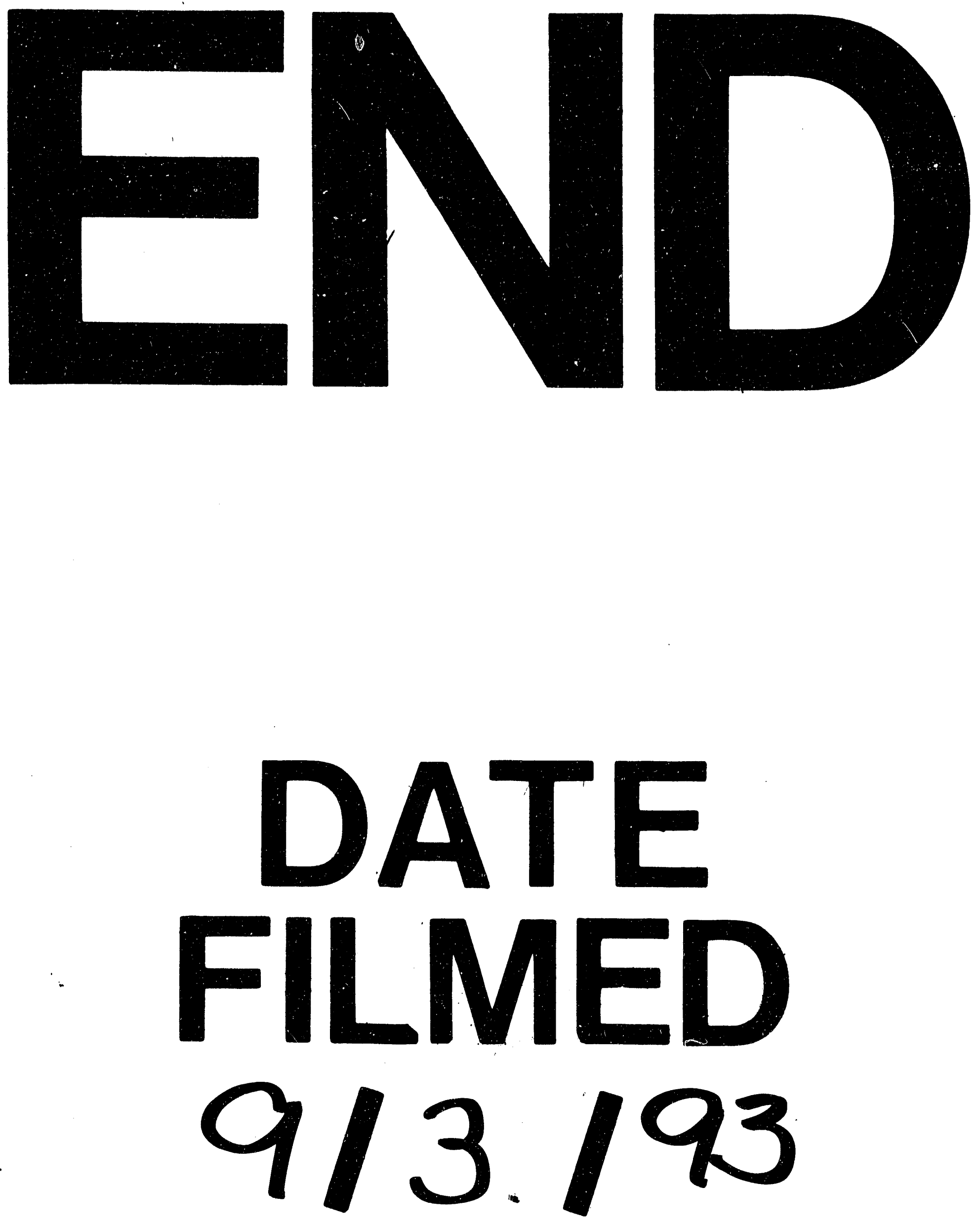
